\title{
Role of Venous Lactate in Predicting Outcomes in Patients with Acute Upper Gastro-Intestinal Bleeding Nahla El-Sayed El-Gammal ${ }^{1}$, Alaa Magdy Mohamed EL Arini*1, Nahla Ibrahim El-Attar ${ }^{2}$, Ahmed Attia Abdel-Moaty ${ }^{1}$, Soha Alhwary ${ }^{1}$
}

Departments of Tropical Medicine and Clinical Pathology, Faculty of Medicine - Zagazig University, Egypt

*Corresponding Author: Alaa Magdy Mohamed EL Arini, Mobile: (+20) 01129813441,

Email: magdymohamedalaa@gmail.com

\begin{abstract}
Background: Several risk scores were clinically assessed for risk stratification of patients with UGIB including Glascow-Blatchford score (GBS) and Rockall score pre and post endoscopy. Many studies tried to detect value of lactate as a predictor of mortality but its role in association with other systems is not well defined.

Objective: To deduct the role of lactate and other scoring systems in assessment of outcomes of UGIB.

Patients and Methods: We conducted a prospective cohort study of patients admitted to ICU of Tropical Medicine Department, Zagazig University Hospitals through the period from December 2019 to March 2020 with a charted diagnosis of upper gastrointestinal bleeding (UGIB).

Results: Regarding performance of GBS, Rockall score and lactate among the studied group, cutoff point of GBS was equal or less than 10.5 can be used as a predictor for recovery with sensitivity of $63.6 \%$, specificity $100 \%$. Cut off of Pre Rockall score was less than or equal to 4.5 can be used as a predictor for recovery with sensitivity of $60.6 \%$, specificity of $80 \%$. As regards venous lactate, cutoff point was equal to or less than 1.85 can be used as a predictor for recovery with sensitivity of $75.8 \%$ and specificity of $100 \%$. Regarding lactate clearance, the cutoff point of equal to or more than $18.8 \%$ can be used as a predictor for active bleeding with sensitivity of $63.2 \%$ and specificity of $42 \%$.

Conclusion: Elevated venous lactate in association with GBS, Rockall scoring systems were found as independent predictor factors for ICU admission, transfusion, endoscopy, length of hospital stay and mortality in patients with acute UGIB.
\end{abstract}

Keywords: Lactate-Prediction, Outcomes, Acute Upper Gastro, Intestinal Bleeding.

\section{INTRODUCTION}

Acute upper gastrointestinal bleeding (AUGIB) is a common emergency condition that ranges in severity from mild symptoms that do not require any interventions, to a life-threatening presentations with hemorrhagic shock that require emergency endoscopy or surgery. It has been estimated to account for up to 20,000 deaths annually in the United States ${ }^{(\mathbf{1}, \mathbf{2})}$. Several well-validated risk stratification tools have been developed specifically for UGIB. The most commonly used being the GBS, Rockall, and AIM65 scores. These scoring systems are based on clinical, laboratory, and endoscopic findings ${ }^{(3,4)}$. Emergent endoscopy and endoscopic findings are often unavailable at the time of initial assessment. Therefore, risk-scoring systems based on clinical and laboratory parameters may be more useful to a clinician at the time of initial assessment ${ }^{(5)}$.

Venous lactate is predictive of the severity of illness and risk of mortality in patients with sepsis. Also, it was found that serum lactate and its serial change (lactate clearance) have been suggested as possible predictor of patient outcome in several critical care conditions ${ }^{(6,7)}$, but little is known about the role of lactate measurement in the triage of patients with acute UGIB ${ }^{(8)}$. The aim of the present study was to deduct the role of lactate and other scoring systems in assessment of outcomes of UGIB.

\section{PATIENTS AND METHODS}

A prospective cohort study was performed including patients $\geq 18$ years old who presented to intensive care unit of Tropical Medicine Department, Zagazig University Hospitals in between November 2019 and March 2020. Patient's demographic information, medical history, and clinical and laboratory data were collected. Patient characteristics included age, gender and comorbidities. Other clinical and laboratory variables included history of prior GIB, history of alcohol abuse, history of smoking, use of nonsteroidal anti-inflammatory drugs (NSAID), use of aspirin, use of anticoagulant, presentation with syncope, bright red blood per rectum, melena, abdominal pain, hematemesis, altered mental status, ascites, initial heart rate and systolic blood pressure, initial hemoglobin, platelet count, prothrombin time as international normalized ratio(INR), creatinine, and venous lactate.

The range of normal venous lactate was defined as normal $0.5-2.0 \mathrm{mmol} / \mathrm{L}$. Accordingly the venous lactate was predefined as normal $(0.5-2 \mathrm{mmol} / \mathrm{liter})$ or elevated (> $2.0 \mathrm{mmol} / \mathrm{L}$ ). Intensive care unit (ICU) admissions, upper endoscopy, packed red blood cell (PRBC) transfusion (transfusion of at least a unit of PRBC) were assessed as outcomes (categorical outcome variables). Two groups were also compared for any difference in

This article is an open access article distributed under the terms and conditions of the Creative Commons Attribution (CC BY-SA) license (http://creativecommons.org/licenses/by/4.0/) 
the length of hospital stay. The data accessed were deidentified and did not require patient informed to access.

\section{Ethical consent :}

An approval of the study was obtained from Zagazig University Academic and Ethical Committee. Every patient signed an informed written consent for acceptance of the operation. This work has been carried out in accordance with The Code of Ethics of the World Medical Association (Declaration of Helsinki) for studies involving humans.

\section{Statistical analysis}

All data were collected, tabulated and statistically analyzed using SPSS version 19. Continuous Quantitative variables were expressed as the mean \pm SD $\&$ median (range), and categorical qualitative variables were expressed as absolute frequencies (number) \& relative frequencies (percentage).

Continuous data were checked for normality by using Shapiro Walk test. Independent samples Student's t-test was used to compare two groups of normally distributed data. Mann-Whitney test was used to compare two groups of not-normally distributed data. Paired t test was used to compare two related groups of normally distributed data. Wilcoxon-sign rank test was used to compare two related groups of not-normally distributed data. Categorical data were compared using Chi-square test $\left(\chi^{2}\right.$ test). All tests were two sided. Pvalue $\leq 0.05$ was considered statistically significant (S), p-value $<0.001$ was considered highly statistically significant (HS), and p-value > 0.05 was considered statistically insignificant (NS).

\section{RESULTS}

Table (1) showed that the age of the studied participants ranged between 30 and 77 years with mean of $56.1 \pm 11.5$ years. More than half of them were males $(65.8 \%)$. As regarding smoking status, $10.5 \%$ of them were smokers.

Table (2) showed that the commonest presenting symptom among the studied participants was melena $(94.7 \%)$ followed by hematemesis $(73.5 \%)$. Active bleeding was detected among $71.1 \%$ of the patients.

Table (3) showed that $15.8 \%$ of patients received NSAIDs, the same frequency for aspirin and anticoagulant use was detected (2.6\% for each). As regards packed RBCs transfusion, almost quarter of patients received three units $(23.7 \%)$, about $15.8 \%$ received two units.

Table (4) showed that mean $\mathrm{Hb}$ was $8.30 \mathrm{~g} / \mathrm{dl}$, mean HCT was $24.2 \%$, mean platelets 109.2 (mCL), total bilirubin was $2.95(\mu \mathrm{mol} / \mathrm{L})$, total PT was 6.7 , mean albumin was $2.78(\mathrm{~g} / \mathrm{L})$, mean AST was $40.2 \mathrm{IU}$, mean ALT was $32.4(\mathrm{U} / \mathrm{L})$, mean creatinine $1.27(\mathrm{mg})$, mean U/N was 29.2 , mean INR was 1.3 , mean PT was 13.2. As regarding venous lactate, mean initial one was
$2.1 \pm 0.78$ and second one was $1.86 \pm 1.17$ and mean lactate clearance was $13.1 \pm 56.6$.

Table (5) showed that the mean GBS was 9.81 that of pre Rockall score was 4.13 and the complete Rockall was 5.31 .

The mean diastolic blood pressure among patients was $63.5 \pm 14.7$ and that of systolic was $99.4 \pm 22.7$ $\mathrm{mm} / \mathrm{Hg}$. Mean heart rate was $96.4 \pm 12.9$ beats $/ \mathrm{min}$. The mean hospital stay was almost 3 days. In this study, endoscopic findings revealed that esophageal varices were found in $19(50 \%)$ of patients, post band ulcer were found in $2(5 \%)$, fundal varix was found in $2(5 \%)$ but prominent fundal vein was found in $1(2.5 \%)$, post sclerosant fundal ulcer was found in $1(2.5 \%)$ and ulcers in D1were found in 5 (13.2\%). Pre pyloric erosions were found in $3(7.9 \%)$, PHG was found in $8(21 \%)$, oesophagitis was found in $2(5 \%)$, moniliasis was found in $1(2.5 \%)$ and incompetent cardia was found in $1(2.5 \%)$ as shown in table (6).

Table (7) showed that five out of 38 patients died (13.2\%). There were non-significant differences between both groups (survivors and non-survivors) as regards initial venous lactate and lactate clearance. However, the difference between them was significant regarding second venous lactate and length of hospital stay, which were both found to be higher among nonsurvivors compared to survivors $(4,4$ days versus 1.5 and 2 days respectively). As regarding comparing initial and second venous lactate among survivor group, it was found that second venous lactate was significantly lowered among them (1.5 versus 2 respectively).

There were non-significant differences between both groups (survivors and non-survivors) as regards complete Rockall score. However, the difference between them was significant regarding GBS and preRockall, which were both found to be higher among non-survivors compared to survivors $(12.8,5.4$ versus 9.36 and 3.93 respectively). By comparing pre- and complete Rockall score among survivor group, it was found that complete Rockall significantly increased among them (5.30 versus 3.93 respectively) as shown in table (8). Table (9) showed that cutoff point of GBS equal to or less than 10.5 can be used as a predictor for recovery with sensitivity of $63.6 \%$, specificity of $100 \%$. Cutoff of pre- Rockall score less than or equal to 4.5 can be used as a predictor for recovery with sensitivity of $60.6 \%$, specificity of $80 \%$. As regards second venous lactate, cutoff point equal to or less than 1.85 can be used as a predictor for recovery of AUGIB with sensitivity of $75.8 \%$ and specificity of $100 \%$.

There was positive significant correlation between GBS and hemoglobin, HCT, ALT, AST, U/N, INR, PT, length of hospital stays, pre-Rockall and complete Rockall. Regarding complete Rockall score, it was found to be positively correlated with GBS and preRockall, however there was a negative significant correlation between it and diastolic and systolic blood pressure, hemoglobin and HCT (Table 10). 
Table (1): Baseline characteristics of the studied group

\begin{tabular}{|c|c|c|}
\hline Variable & \multicolumn{2}{|c|}{$\begin{array}{c}\text { Studied group } \\
(\mathrm{n}=\mathbf{3 8})\end{array}$} \\
\hline \multirow{3}{*}{$\begin{array}{l}\text { Age: } \\
\text { - Mean } \pm \text { SD } \\
\text { - Range }\end{array}$} & \multirow{2}{*}{\multicolumn{2}{|c|}{$\begin{array}{c}56.1 \pm 11.5 \\
30-77\end{array}$}} \\
\hline & & \\
\hline & No & $\%$ \\
\hline \multicolumn{3}{|l|}{ Sex: } \\
\hline - Female & 13 & 34.2 \\
\hline - Male & 25 & 65.8 \\
\hline \multicolumn{3}{|l|}{ Smoking: } \\
\hline - Yes: & 4 & 10.5 \\
\hline - No: & 34 & 89.5 \\
\hline \multicolumn{3}{|l|}{ Alcohol use: } \\
\hline - Yes: & 0 & 0 \\
\hline - No: & 38 & 100 \\
\hline
\end{tabular}

Table (2): Symptoms detected and medical history among the studied group

\begin{tabular}{|c|c|c|}
\hline \multirow[t]{2}{*}{ Variable } & \multicolumn{2}{|c|}{$\begin{array}{c}\text { Studied group } \\
\quad(n=38)\end{array}$} \\
\hline & No & $\%$ \\
\hline $\begin{array}{l}\text { Hematemesis: } \\
\text { - No: } \\
\text { - Yes: }\end{array}$ & $\begin{array}{l}10 \\
28\end{array}$ & $\begin{array}{l}26.5 \\
73.5\end{array}$ \\
\hline $\begin{array}{l}\text { Melena: } \\
\text { - No: } \\
\text { - Yes: }\end{array}$ & $\begin{array}{c}2 \\
36\end{array}$ & $\begin{array}{c}5.3 \\
94.7\end{array}$ \\
\hline $\begin{array}{l}\text { Abdominal pain: } \\
\text { - No: } \\
\text { - Yes: }\end{array}$ & $\begin{array}{c}33 \\
5\end{array}$ & $\begin{array}{l}86.8 \\
13.2\end{array}$ \\
\hline $\begin{array}{l}\text { Ascites: } \\
\text { - No: } \\
\text { - Yes: }\end{array}$ & $\begin{array}{c}30 \\
8\end{array}$ & $\begin{array}{l}78.9 \\
21.1\end{array}$ \\
\hline $\begin{array}{l}\text { Altered mental status: } \\
\text { - No: } \\
\text { - Yes: }\end{array}$ & $\begin{array}{c}35 \\
3\end{array}$ & $\begin{array}{c}92.1 \\
7.9\end{array}$ \\
\hline $\begin{array}{l}\text { Syncope: } \\
\text { - No: } \\
\text { - Yes: }\end{array}$ & $\begin{array}{c}34 \\
4\end{array}$ & $\begin{array}{l}89.5 \\
10.5\end{array}$ \\
\hline $\begin{array}{l}\text { Active bleeding : } \\
\text { - No: } \\
\text { - Yes: }\end{array}$ & $\begin{array}{l}11 \\
27\end{array}$ & $\begin{array}{l}28.9 \\
71.1\end{array}$ \\
\hline
\end{tabular}


Table (3): Past history and co association

\begin{tabular}{|l|c|c||}
\hline \multirow{2}{*}{ Variable } & \multicolumn{2}{|c|}{ Studied group (n=38) } \\
\cline { 2 - 3 } NSAIDs: & No & \% \\
- No: & 32 & 84.2 \\
- Yes: & 6 & 15.8 \\
\hline Aspirin use: & & \\
- No: & 37 & 97.4 \\
- Yes: & 1 & 2.6 \\
\hline Anticoagulant use: & & \\
- No: & 37 & 97.4 \\
- Yes: & 1 & 2.6 \\
\hline Previous upper GIT bleeding: & & \\
- No: & 19 & 50 \\
- Yes: & 19 & 50 \\
\hline Packed RBCs transfusion: & & \\
- No: & 16 & 42.1 \\
- One: & 2 & 5.3 \\
- Two: & 6 & 15.8 \\
- Three: & 9 & 23.7 \\
- Four: & 3 & 7.9 \\
- Five: & 1 & 2.6 \\
- Eight: & 1 & 2.6 \\
\hline
\end{tabular}

Table (4): Laboratory parameters of the studied group

\begin{tabular}{|l|c|}
\hline \multicolumn{1}{|c|}{ Variable } & $\begin{array}{c}\text { Studied group }(\mathbf{n}=\mathbf{3 8}) \\
\text { Mean } \pm \text { SD }\end{array}$ \\
\hline $\begin{array}{l}\text { Hemoglobin: } \\
\bullet \text { Male }(12-16)\end{array}$ & \\
\hline Female $(10-14)$ & $8.30 \pm 2.12$ \\
\hline HCT & $24.2 \pm 5.05$ \\
\hline WBCs: $(\mathrm{mcL})$ & $9.60 \pm 5.73$ \\
\hline Platelets: $(\mathrm{mcL})$ & $109.2 \pm 30.1$ \\
\hline Total bilirubin: $(\mu \mathrm{mol} / \mathrm{L})$ & $2.95 \pm 0.64$ \\
\hline Total PT: & $6.77 \pm 1.76$ \\
\hline Albumin $(\mathrm{g} / \mathrm{L})$ & $2.78 \pm 0.86$ \\
\hline ALT: $(\mathrm{U} / \mathrm{L})$ & $32.4 \pm 9.6$ \\
\hline AST: $(\mathrm{U} / \mathrm{L})$ & $40.2 \pm 9.4$ \\
\hline Creatinine: $(\mathrm{mg})$ & $1.27 \pm 0.23$ \\
\hline Urea/N: $(\mathrm{mg} / \mathrm{dL})$ & $29.2 \pm 2.9$ \\
\hline INR & $1.31 \pm 0.53$ \\
\hline PT: $:$ : & $13.2 \pm 2.9$ \\
\hline Initial venous lactate & $2.10 \pm 0.48$ \\
\hline Second venous lactate: & $1.86 \pm 0.17$ \\
\hline Lactate clearance $(\%):$ & $13.1 \pm 6.6$ \\
\hline
\end{tabular}

Table (5): Different scores of the studied group

\begin{tabular}{|l|c|}
\hline \multicolumn{1}{|c|}{ Variable } & $\begin{array}{c}\text { Studied group }(\mathbf{n}=\mathbf{3 8}) \\
\text { Mean } \pm \text { SD }\end{array}$ \\
\hline GBS: & $9.81 \pm 3.06$ \\
\hline Pre ROCKALL: & $4.13 \pm 1.45$ \\
\hline Complete ROCKALL: & $5.31 \pm 1.49$ \\
\hline
\end{tabular}


Table (6): Clinical parameters of the studied group

\begin{tabular}{|l|c|}
\hline \multicolumn{1}{|c|}{ Variable } & $\begin{array}{c}\text { Studied group } \\
(\mathbf{n = 3 8}) \\
\text { Mean } \pm \text { SD }\end{array}$ \\
\hline Time of onset of bleeding: & $6.63 \pm 24.1$ \\
\hline Diastolic blood pressure: & $63.5 \pm 14.7$ \\
\hline Systolic blood pressure: & $99.4 \pm 22.7$ \\
\hline Heart rate: & $96.4 \pm 12.9$ \\
\hline Length of hospital stay: & $2.71 \pm 1.45$ \\
\hline
\end{tabular}

Table (7): Mortality rate among the studied group

\begin{tabular}{|c|c|c|}
\hline \multirow[t]{2}{*}{ Variable } & \multicolumn{2}{|c|}{$\begin{array}{l}\text { Studied group } \\
(n=38)\end{array}$} \\
\hline & No & $\%$ \\
\hline $\begin{array}{c}\text { Mortality: } \\
\text { - No: } \\
\text { - Yes: }\end{array}$ & $\begin{array}{c}33 \\
5\end{array}$ & $\begin{array}{l}86.8 \\
13.2\end{array}$ \\
\hline
\end{tabular}

Table (8): Relationship between mortality and venous lactate among the studied groups and the relationship between mortality and GBS, Pre-Rockall and complete Rockall score among the studied groups

\begin{tabular}{|c|c|c|c|c|}
\hline Variable & $\begin{array}{c}\text { Survivors } \\
(n=33)\end{array}$ & $\begin{array}{c}\text { Non-survivors } \\
(n=5)\end{array}$ & Test & P-value \\
\hline $\begin{array}{l}\text { Initial venous lactate: } \\
\text { - Median }\end{array}$ & 2 & 2.9 & -1.709\# & $\begin{array}{l}0.093 \\
(\mathrm{NS})\end{array}$ \\
\hline $\begin{array}{l}\text { Second venous lactate: } \\
\text { - Median }\end{array}$ & 1.5 & 4 & $-3.568 \#$ & $\begin{array}{c}<0.001 \\
(\text { HS) }\end{array}$ \\
\hline P-value\$ & $<0.001(\mathrm{HS})$ & $0.138(\mathrm{NS})$ & & \\
\hline $\begin{array}{l}\text { Lactate clearance }(\%) \text { : } \\
\text { - Median }\end{array}$ & 22 & 20 & $-0.821 \#$ & $\begin{array}{l}0.424 \\
(\mathrm{NS})\end{array}$ \\
\hline $\begin{array}{l}\text { Length of hospital stay: } \\
\text { - Median }\end{array}$ & 2 & 4 & $-2.210 \#$ & $\begin{array}{c}\mathbf{0 . 0 3} \\
(\mathbf{S})\end{array}$ \\
\hline $\begin{array}{l}\text { GBS: } \\
\quad \text { - Median }\end{array}$ & $9.36 \pm 2.94$ & $12.8 \pm 2.16$ & -2.495 & $\begin{array}{c}\mathbf{0 . 0 1} \\
(\mathrm{S})\end{array}$ \\
\hline $\begin{array}{l}\text { Pre ROCKALL: } \\
\text { - Mean } \pm \text { SD }\end{array}$ & $3.93 \pm 0.41$ & $5.40 \pm 1.14$ & -2.197 & $\begin{array}{c}\mathbf{0 . 0 3} \\
(\mathbf{S})\end{array}$ \\
\hline $\begin{array}{l}\text { Complete ROCKALL: } \\
\text { - Mean } \pm \text { SD }\end{array}$ & $5.30 \pm 1.55$ & $5.40 \pm 1.14$ & -0.134 & $\begin{array}{l}0.894 \\
(\mathrm{NS})\end{array}$ \\
\hline P-value ${ }^{\wedge}$ & $<0.001(\mathrm{HS})$ & $1.00(\mathrm{NS})$ & & \\
\hline
\end{tabular}

Table (9): Performance of GBS, Rockall score and lactate as predictors of survival among the studied group

\begin{tabular}{|l|c|c|c|c|c|c|}
\hline \multicolumn{1}{|c|}{ Variable } & $\begin{array}{c}\text { Cutoff } \\
\text { Point }\end{array}$ & AUC & Sensitivity & Specificity & 95\% CI & $\begin{array}{c}\text { P } \\
\text { value }\end{array}$ \\
\hline GBS & $\leq 10.5$ & 0.830 & $63.6 \%$ & $100 \%$ & $0.67-0.98$ & $\mathbf{0 . 0 1}$ \\
\hline $\begin{array}{l}\text { Pre } \\
\text { ROCKALL }\end{array}$ & $\leq 4.5$ & 0.788 & $60.6 \%$ & $80 \%$ & $0.60-0.97$ & $\mathbf{0 . 0 4}$ \\
\hline Lactate & $\leq 1.85$ & 1.00 & $75.8 \%$ & $100 \%$ & $1.0-1.0$ & $<\mathbf{0 . 0 0 1}$ \\
\hline
\end{tabular}

Table (10): The correlation between GBS and complete Rockall scores and different parameters among the studied group: 


\begin{tabular}{|c|c|c|c|c|}
\hline \multirow{2}{*}{ Variable } & \multicolumn{2}{|c|}{$\overline{\text { GBS }}$} & \multicolumn{2}{|c|}{ Complete Rockall score } \\
\hline & $\mathbf{R}$ & $\mathbf{P}$ & $\mathbf{r}$ & $\mathbf{P}$ \\
\hline Diastolic blood pressure: (mmHg) & -0.380 & 0.005 & -0.548 & $<0.001$ \\
\hline Systolic blood pressure: (mmHg) & -0.311 & 0.057 & -0.457 & $\mathbf{0 . 0 0 4}$ \\
\hline Heart rate: & 0316 & 0.054 & 0.283 & 0.085 \\
\hline Hemoglobin: (g/dL) & -0.631 & $<0.001$ & -0.329 & 0.04 \\
\hline HCT: & -0.682 & $<0.001$ & -0.451 & 0.005 \\
\hline WBCs: (mcL) & 0.277 & 0.092 & -0.130 & 0.437 \\
\hline Platelets: (mcL) & -0.010 & 0.952 & -0.130 & 0.437 \\
\hline Total bilirubin: $(\mu \mathrm{mol} / \mathrm{L})$ & 0.240 & 0.146 & -0.112 & 0.505 \\
\hline Total PT: & -0.105 & 0.529 & 0.130 & 0.438 \\
\hline Albumin: (g/L) & -0.255 & 0.122 & -0.236 & 0.153 \\
\hline ALT: (U/L) & 0.365 & 0.02 & 0.039 & 0.818 \\
\hline AST: (U/L) & 0.462 & 0.004 & 0.202 & 0.224 \\
\hline Creatinine: (mg) & 0.368 & 0.02 & 0.154 & 0.355 \\
\hline U/N: & 0.530 & 0.001 & 0.115 & 0.493 \\
\hline INR: & 0.371 & 0.02 & 0.011 & 0.946 \\
\hline PT: & 0.340 & 0.03 & -0.015 & 0.927 \\
\hline Initial venous lactate: & 0.238 & 0.151 & 0.179 & 0.281 \\
\hline Lactate clearance: & -0.179 & 0.282 & 0.168 & 0.312 \\
\hline Packed RBCs units: (mcL) & 0.405 & 0.062 & 0.320 & 0.146 \\
\hline Length of hospital stay: (day) & 0.498 & 0.001 & 0.193 & 0.245 \\
\hline GBS: & -- & -- & 0.445 & 0.005 \\
\hline Pre-Rockall: & 0.533 & 0.001 & 0.828 & $<0.002$ \\
\hline Complete ROCKALL: & 0.445 & 0.005 & --- & --- \\
\hline
\end{tabular}

\section{DISCUSSION}

Acute upper gastrointestinal bleeding was and still up till now acommon and challenging emergency being associated to significant morbidity, mortality and health care costs. One of the major challenges in management of AUGIB is identification of high risk patients of mortality, in need for urgent blood transfusion, ICU admission and early endoscopic intervention ${ }^{(9)}$. Many risk fators are known to influence the AUGIB setting outcome among them age, comorbidities, shock, endoscopic diagnosis, haemoglobin level at the bleeding episode, lesions size and /or grade and stigmata of recent hemorrhage ${ }^{(\mathbf{1 0})}$. Several studies documented those elderly patients and those with chronic medical diseases with stand AUGIB less well than younger, fitter patients, and have a higher risk of death ${ }^{(11)}$.

In order to stratify outcome, several clinical scores are in use. Although recommended in the prevailing guidelines, they are erratically applied in the clinical practice. The commonly used systems are the Rockall score, the Baylor leading score, the CedarsSinai Medical Centre Predictive Index, the Blatchford score ${ }^{(12)}$. Initial clinical management decision in patients with acute gastrointestinal bleeding is often based on identifying high and low risk patients.

In the period between November 2019 and March 2020, 38 patients were selected from the patients admitted to ICU and Endoscopy Unit of Tropical Medicine Department to be included in this study. This study aimed to determine role of venous lactate and its serial changes in assosciation with other risk scores (GBS and Rockall score) in predicting outcomes in patients with acute upper gastrointestinal bleeding.

As mentioned before the aim of this study was to assess role of venous lactate and its serial changes in assosciation with other clinical scores as Rockall and GBS to identify patients who are at risk of mortality in need for urgent blood transfusion, ICU admission and early endoscopic intervention. Several studies have shown that the Rockall was closely correlated with mortality rather than rebleeding. ${ }^{(13-15)}$. This may be partly explained by the fact that the Rockall score was originally developed for prediction of mortality rather than rebleeding and because not all patients received endoscopic therapy.

Regarding GBS, it was used for prediction of of clinical outcomes of AUGIB mainly peptic ulcer incorporating 8 clinical or laboratory variables which are as follows heart rate, hemoglobin level, blood urea nitrogen, systolic blood pressure, melena occurrence, syncope, hepatic disease, or heart. The GBS ranges from 0 to 23, with higher likelihood of a need for an endoscopic intervention failure (16). A score of 0 identifies low risk patients who might be suitable for outpatient management, while scores of 6 or more are associated with $>50 \%$ risk of intervention ${ }^{(17)}$.

In our study lactate and its serial changes, GBS, Rocall pre-endoscopy and complete Rocall score were compared to determine their ability to predict the need for blood transfusion, ICU admission, early endoscopic 
intervention, length of hospital stay and mortality rates in patients who are admitted with UGI bleeding.

Hyperlactaemia can be seen in many conditions that results in tissue hypoxia and organ imbalance, such as shock, sepsis, seizures and severe trauma. In anerobic conditions, pyruvate is converted to lactic acid by lactate dehydrogenase. Hyperlctaemia occurring during UGI bleeding is the result of various mechanisms. Hypovolaemia due to haemorrhage results in tissue hypoxia and so more lactate production that can be used due to anaerobic conditions it creates and hyper lactaemia is developed ${ }^{(18)}$. It was determined that mortality is increased as serum lactate level increased. Finally lactate was found to have high senstivity and low specificity ${ }^{(19)}$.

In our study GBS was found to be significantly higher in patients with mortality. Preventing unimportant blood transfusion will prevent post transfusion complications and reduce costs. In our study, red blood transfusion was performed in about $80 \%$ of the patients. The reason for this high rate is that all UGI bleeding patients are frequently refered to our hospital without transfusion. Patients who are older and have more comorbidity should be approached more sensitively when it comes to blood transfusion because of their tolerance to anemia and tissue hypoxia. Patients who underwent transfusions had active bleedings clinically or endoscopically, and transfusions were performed with expectation that their haemodynamic values would decrease rapidly and their hemodynmic status would worsen. Our study also showed that serial elevation in venous lactate was an independent predictor of inpatient endoscopic intervention and long hospital stay. Also, our study showed that there was a significant correlation between venous lactate, and each of WBCs, ALT, length of hospital stay, GBS and pre-Rockall score.

Our study showed that incorporation of venous LA into GBS and RS showed statistically significant improvement in the power of risk scores to determine inpatient mortality status. Importantly, the performance of modified RS-PE was comparable to or better than that of the original RS-post endoscopy, providing vital prognostication and risk stratification for healthcare providers before any diagnostic or therapeutic intervention has taken place.

Our study also showed that serial elevation in venous lactate was an independent predictor of inpatient endoscopic intervention and long hospital stay.

\section{CONCLUSION}

Elevated venous lactate in association with GBS, Rockall scoring systems were found as independent predictor factors for ICU admission, transfusion, endoscopy, length of hospital stay and mortality in patients with acute UGIB. Further prospective studies are needed to validate these findings.

\section{REFERENCES}

1. El-Tawil A (2012): Trends on gastrointestinal bleeding and mortality: where are we standing? World J Gastroenterol., 18 (11): 1154-58.

2. Peery A, Crockett S, Barritt et al. (2015): Burden of Gastrointestinal, Liver, and Pancreatic Diseases in the United States. Gastroenterology, 149 (7): 1731-41.

3. Rockall T, Logan R, Devlin H et al. (1996): Risk assessment after acute upper gastrointestinal haemorrhage. Gut, 38 (3): 316-21.

4. Blatchford O, Murray W, Blatchford M (2000): A risk score to predict need for treatment for upper gastrointestinal haemorrhage. Lancet, 356: 1318-1321.

5. Das A, Wong R (2004): Prediction of outcome of acute GI hemorrhage: a review of risk scores and predictive models. Gastrointest Endosc., 60 (1): 85-93.

6. Zhang Z, Xu X (2014): Lactate clearance is a useful biomarker for the prediction of all-cause mortality in critically ill patients: a systematic review and meta-analysis. Crit Care Med., 42 (9): 2118 25.

7. Musikatavorn K, Thepnimitra S, Komindr et al. (2015): Venous lactate in predicting the need for intensive care unit and mortality among nonelderly sepsis patients with stable hemody-namic. Am J Emerg Med., 33 (7): 925-30.

8. Shresta M, Borgstrom M, Trowers E (2018): Elevated lactate level predicts intensive care unit admissions, endoscopies and transfusions in patients with acute gastrointestinal bleeding. Clin Exp Gastroenterol., 11: 185-92.

9. Lewis J, Bilker W, Brensinger C et al. (2002): Hospitalization and mortality rates from peptic ulcer disease and gastrointestinal bleeding in 1990s:relationship to sales of non steroidal antiinflammatory drugs and acid suppression medications. Am J Gastroenterol., 97: 2540-9.

10. Wang C, Qin J, Wang J et al. (2013): Rocckall score in predicting outcomes of elderly patients with acute upper gastrointestinal bleeding. World J Gastroenterol., 19: 3466-72.

11. Hearnshaw S, Logan R, Lowe D et al. (2011): Acute upper gastrointestinal bleeding in the UK: Patient charactristics, diagnosis and outcomes in the 2007 UK audit. Gut, 60: 1327-35.

12. Camellini L, Merighi A, Pagnini C et al. (2004): Comparison of three different risk scoring systems in non variceal upper gastrointestinal bleeding. Dig liver Dis., 36: 271-277.

13. Bessa $X$, O'Callaghan E, Balleste B et al. (2006): Applicability of the Rockall score in patients undergoing endoscopic therapy for upper gastrointestinal bleeding. Dig liver Dis., 38: 12-17.

14. Enns R, Gagnon Y, Barkun A et al. (2006): Validation of the Rockall scoring system for outcomes from non-variceal upper gastrointestinal bleeding in a Canadian setting. World J Gastroenterol., 12: 7779-7785.

15. Kim B, Park M, Kim S et al. (2009): Comparison of scoring systems for the prediction of outcomes in patients with nonvariceal upper gastrointestinal bleeding: a prospective study. Dig Dis Sci., 54: 2523-2529.

16. Govedarica S, Hadzibulic E (2007): Significance of forrest classification, Rocall and Blatchford risk scoring system in prediction of rebleeding in piptic ulcer disease. Acta Medica Medianae, 46: 38-43.

17. Stanley A, Ashley D, Dalton H et al. (2009): Outpatient management of patients with low-risk upper gastrointestinal haemorrhage: multicenter validation and prospective evaluation. Lancet, 373: 42-7

18. Shah A, Chisolm-Straker M, Alexander A et al. (2014): Prognostic use of lactate to predict inpatient mortality in acute gastrointestinal hemorrhage. Am J Emerg Med., 32 (7): 752-5.

19. El Kersh K, Chadha U, Sinha $R$ et al. (2015): Predictive role of admission of lactate level in critically ill patients with acute upper gastrointestinal bleeding. The Journal of Emergency Medicine, 49: 318-325. 